\title{
PRÁTICAS INOVADORAS NO ENSINO DE GRADUAÇÃO NA PERSPECTIVA DE PROFESSORES UNIVERSITÁRIOS
}

\author{
INNOVATIVE PRACTICES IN HIGHER \\ EDUCATION FROM THE PERSPECTIVE OF \\ PROFESSORS
}

Beatriz S. C. Cortela ${ }^{1}$

\section{RESUMO}

Este trabalho traz reflexões sobre as práticas de docentes universitários que atuam como formadores em cursos de licenciatura. Objetiva apontar o que um grupo deles, que ministra aulas em diferentes cursos de uma universidade pública, entende por práticas inovadoras no ensino de graduação a partir da descrição que fazem das atividades que realizam. Os dados foram levantados com base em resumos apresentados num evento científico e foram analisados dentro do referencial de análise de conteúdo, de Bardin. Os resultados apontam que a maioria dos autores considera que as atividades desenvolvidas por eles são uma nova forma de trabalho para si, mas não necessariamente original; apresentam potencial de melhoria no processo de aprendizagem; fazem menção ao uso de metodologias ativas e não associadas, necessariamente, ao uso de tecnologias. Estudos sobre essa temática auxiliam na elucidação dos fatores que envolvem o processo de construção de uma identidade docente no ensino superior.

${ }^{1}$ Universidade Estadual Paulista (UNESP),

Bauru, Brasil. 
Palavras-chave: Docência universitária. Práticas inovadoras. Ensino de graduação. Identidade docente.

\section{INTRODUÇÃO}

O presente artigo é um excerto de uma pesquisa que está sendo realizada com o intuito de aprofundar estudos a respeito das práticas de docentes universitários que atuam como formadores em cursos de licenciatura na área de ciências da natureza. Visa compreender as múltiplas relações que envolvem a mobilização de saberes durante as atividades de ensino que realizam, ou seja, elucidar os fatores que envolvem o processo de construção de uma identidade docente.

Restringiu-se o enfoque da pesquisa às práticas de docentes universitários que atuam em uma universidade pública e em cursos de licenciatura da área, uma vez que pensar em princípios e processos formativos requer levar em conta o cenário e o contexto da atuação dos sujeitos. Como bem considera Almeida (2012), os professores das faculdades ou universidades particulares, em sua maioria, não se dedicam à atividades de pesquisa e/ou extensão. Ocupam-se, primordialmente, com as atividades de ensino e têm pouca influência na definição dos rumos pedagógicos das instituições onde trabalham, dentro de certa instabilidade empregatícia, condições diversas daquelas enfrentadas por docentes que atuam em universidades públicas.

Quanto à escolha por aqueles que atuam como formadores em cursos de licenciatura, esta se deve ao campo de atuação e às 
especificidades desse profissional: ensinar a ensinar. $\mathrm{Na}$ fala ${ }^{1}$ da professora Maria Isabel Cunha: "É preciso ensinar Geografia ao Joãozinho". Ou seja, comprometer-se com a aprendizagem, fazer a transposição didática de um conteúdo específico para um indivíduo, levando em conta as particularidades de cada sujeito, mesmo trabalhando numa sala repleta de alunos com outras especificidades e demandas.

Apresentam-se aqui as análises referentes a um levantamento realizado com o propósito de conhecer as práticas docentes que estão sendo desenvolvidas no âmbito de uma instituição de ensino superior (IES) e que são compreendidas pelos próprios sujeitos como "inovadoras". Os dados foram coletados a partir dos trabalhos apresentados em um evento promovido em 2013 (OLIVEIRA; SPAZZIANI; OLIVA, 2014).

\section{O DOCENTE UNIVERSITÁRIO: FORMAÇÃO E PRÁTICAS PEDAGÓGICAS}

A docência universitária vem se constituindo um campo interessante de pesquisa nas últimas décadas, e diversos autores têm se dedicado ao tema (ALARCÃO, 1998; ALMEIDA, 2012; CUNHA, 2004, 2010; GARCIA, 1999; GAUTHIER et al., 1998; MASETTO, 2002, 2003; NÓVOA, 1992; PIMENTA; ANASTASIOU, 2002; PIMENTA; GHEDIN, 2006; ZABALZA, 2004), dentre outros.

\footnotetext{
${ }^{1}$ Palestra proferida em mesa redonda, realizada em 12 jun. 2013, sobre o tema "Metodologias do ensino superior para a UNESP do século XXI", evento promovido pela Pró-Reitoria de Graduação da Universidade Estadual Paulista (UNESP).
} 
Esse campo de investigação, relacionado à pedagogia universitária, tem apontado diferentes problemáticas, sobretudo aquelas que se referem às lacunas de ordem didáticopedagógicas presentes nas práticas de muitos dos docentes do ensino superior. Como bem considera Almeida (2012), a maioria dos professores universitários têm dificuldade em admitir e reconhecer a importância das dimensões didáticas e pedagógicas no ato de ensinar. Argumenta que essa resistência é decorrente, dentre outras causas, da herança do paradigma hegemônico das ciências exatas e da natureza, segundo a qual os conteúdos específicos recebem mais ênfase na formação inicial que aqueles de natureza didático-pedagógica.

Muito de senso comum ainda permeia a atividade docente, como aponta Masetto (2002), dentre outros. A começar pela ideia, criticada pelo autor, de que "[...] quem sabe, automaticamente, sabe ensinar" (MASETTO, 2002, p. 61), o que não é necessariamente verdadeiro. $O$ fato de uma pessoa ser alfabetizada, por exemplo, não garante que ela seja capaz de alfabetizar dezenas de crianças em uma sala sem cometer deslizes e/ou causar danos ao desempenho posterior dessas crianças.

O exercício da docência exige capacitação específica. No entanto, no caso dos docentes universitários, essa especificidade às vezes é desconsiderada em função do fator pesquisa.

Em primeiro lugar, é necessário salientar que o prestígio profissional (reconhecimento social, capacidade de influência, recompensas intrínsecas e extrínsecas, etc.) Ihe é proporcionado exclusivamente pela actividade de investigação e pela produção 
científica. Assim, uma medíocre atitude didactica pode ser recompensada se o professor for bom investigador (PÉREZ, 1989 apud GARCIA, 1999, p. 24).

Diversos autores (ALMEIDA, 2012; CUNHA, 2010; MASETTO, 2003) apontam que a maioria dos professores universitários, não só no Brasil, não têm o devido preparo pedagógico para atuar em atividades de ensino, repetindo, como docentes, o mesmo modelo formativo que receberam durante as graduações, principalmente aqueles que ministram disciplinas específicas em cursos da área de ciências da natureza, a maior parte deles oriunda de cursos de bacharelado e com pós-graduação em áreas específicas, não ligadas ao ensino (CORTELA, 2013).

Outra concepção simplista, e não necessariamente correta, é a de que "[...] para ser docente, basta ser um bom profissional em sua área" (MASETTO, 2002, p. 62). Concordando-se com essa crítica, não se pode reduzir a formação docente ao domínio de conteúdos específicos do campo de atuação em que se está inserido nem à vocação de cada um, uma vez que ensaio e erro irão, provavelmente, caracterizar a caminhada acadêmica do profissional.

$\mathrm{Na}$ maioria das instituições de ensino superior, incluindo as universidades, embora seus professores possuam experiência significativa e mesmo anos de estudos em suas áreas específicas, predomina um despreparo e até um desconhecimento científico do que seja o processo de ensino e de aprendizagem, pelo qual passam a ser responsáveis a partir do instante em que ingressam na sala de aula (PIMENTA; ANASTASIOU, 2002, p. 37). 
As concepções anteriormente enunciadas foram assim constituídas porque, muitas vezes, são condições suficientes para o modelo de ensino adotado pela maioria das universidades: centrado no professor, nos conteúdos que ele julga serem necessários à formação do aluno, modelo em que aprender, na maioria dos casos, significa repetir nas provas o que o foi apresentado em sala de aula.

No entanto, o atual modelo para formação de professores, pelo menos no discurso, aponta em outra direção. Desde a aprovação das Diretrizes Curriculares para Formação de Professores, CNE/CP 01/2002 (BRASIL, 2002), passando pela Deliberação 126/2014 (SÃO PAULO, 2014) e chegando ao ideário das atuais Diretrizes Curriculares Nacionais para formação inicial em nível superior, CNE/CP 02/2015 (BRASIL, 2015), a perspectiva é a formação baseada nas racionalidades prática e/ou crítica, buscando a interdisciplinaridade, superando a fragmentação dos conteúdos e fazendo uso de metodologias de ensino ativas. No entanto, a afirmação "[...] o ensino nas universidades, de maneira geral, ainda não absorveu as necessidades do momento histórico" (MASETTO, 2002, p. 63), continua bastante atual (CORTELA, 2013).

Zabalza (2004, p. 169-177), ao comentar sobre os desafios da formação de docentes universitários, defende que os programas de formação deveriam contemplar as seguintes linhas básicas: a passagem de uma docência baseada no ensino para aquela pautada na aprendizagem; o estágio prático; a flexibilização dos currículos; a busca da qualidade através da revisão das práticas docentes; e a incorporação de novas tecnologias. O levantamento aqui apresentado visa 
ao enfrentamento, dentre outros, dos dois últimos desafios anteriormente citados.

\section{INOVAÇÃO EDUCACIONAL: UMA EXPRESSÃO POLISSÊMICA}

O perfil dos alunos universitários e o contexto em que estão inseridos se modificam de tempos em tempos, atualmente, de forma mais intensa. Hernández et al. (2000) apontam para a necessidade de que ocorram mudanças periódicas e/ ou contínuas na maneira de se organizar e se pôr em prática o ensino. Mas as justificativas para que essas ocorram não podem estar vinculadas somente às tecnologias e/ou àquelas mudanças que ocorrem na base produtiva, ou mesmo almejando inovações. E quando se pode afirmar que uma mudança é também uma inovação?

Para Goldberg (1995) a definição desse conceito é uma espécie de saga, pois envolve uma série de vicissitudes. Não se trata de um problema novo, uma vez que vários autores já se dedicam a isso há tempos, e continuam a fazê-lo. Vejamos algumas definições, buscando um mapeamento sobre o que já se tem produzido. 
Quadro 1 - Conceito de inovação na perspectiva de diferentes autores

\begin{tabular}{|c|c|}
\hline Definição & Autor(es) \\
\hline $\begin{array}{l}\text { "Inovação é um termo enganoso, sedutor e } \\
\text { equívoco ao mesmo tempo: sedutor porque } \\
\text { sugere aperfeiçoamento, progresso quando } \\
\text { em realidade significa algo novo e diferente. } \\
\text { Equívoco porque desvia a atenção da essência } \\
\text { da atividade de que trata o ensino com vista } \\
\text { aos problemas da tecnologia da educação". }\end{array}$ & $\begin{array}{l}\text { (WESDEY, } 1969 \\
\text { apud GOLDBERG, } \\
\text { 1995, p. 204). }\end{array}$ \\
\hline $\begin{array}{l}\text { "Uma inovação é um aperfeiçoamento que } \\
\text { se pode medir, deliberado, duradouro e } \\
\text { com poucas possibilidades de ocorrer com } \\
\text { frequência". }\end{array}$ & $\begin{array}{l}\text { (HUBERMAN, } \\
1973 \text { apud } \\
\text { GOLDBERG, 1995, } \\
\text { p. 204). }\end{array}$ \\
\hline $\begin{array}{l}\text { “Há também uma distinção entre 'mudança' } \\
\text { e 'inovação'. O segundo conceito refere-se a } \\
\text { algo mais deliberado, intencional, planificado } \\
\text { e não algo que ocorre espontaneamente”. }\end{array}$ & $\begin{array}{l}\text { (MILLES, } 1974 \\
\text { apud GOLDBERG, } \\
\text { 1995, p. 204). }\end{array}$ \\
\hline $\begin{array}{l}\text { "Inovação é o processo planejado e } \\
\text { científico de desenvolver e implantar no } \\
\text { sistema educacional uma mudança, cujas } \\
\text { possibilidades de ocorrer com frequência são } \\
\text { poucas, mas cujos efeitos representam um } \\
\text { real aperfeiçoamento para o sistema". }\end{array}$ & $\begin{array}{l}\text { (GOLDBERG et } \\
\text { al., } 1977 \text { apud } \\
\text { GOLDBERG, 1995, } \\
\text { p. 204). }\end{array}$ \\
\hline $\begin{array}{l}\text { "Inovar significa introduzir mudanças num } \\
\text { objeto de forma planejada visando produzir } \\
\text { melhoria no mesmo". }\end{array}$ & $\begin{array}{l}\text { (FERRETTI, 1995, } \\
\text { p. 62). }\end{array}$ \\
\hline
\end{tabular}

(continua) 


\begin{tabular}{|c|c|}
\hline Definição & Autor(es) \\
\hline $\begin{array}{l}\text { "Inovação é a seleção criadora, a organização } \\
\text { e a utilização de recursos humanos e } \\
\text { materiais de uma forma nova e original que } \\
\text { conduza a uma melhor consecução dos fins e } \\
\text { objetivos definidos". }\end{array}$ & $\begin{array}{l}\text { (RICHLAND, } 1995 \\
\text { apud GOLDBERG, } \\
\text { 1995, p. 204). }\end{array}$ \\
\hline $\begin{array}{l}\text { “[...] Em termos gerais, pode-se dizer que } \\
\text { uma inovação é, como assinala Hord (1987), } \\
\text { 'qualquer aspecto novo para um indivíduo } \\
\text { dentro de um sistema'. [...] Assim, a inovação } \\
\text { não é a mesma para quem a promove, para } \\
\text { quem a facilita, para quem a põe em prática } \\
\text { ou para quem recebe seus efeitos. Portanto, } \\
\text { a definição do que constitui uma inovação } \\
\text { resulta da confluência de uma pluralidade de } \\
\text { olhares”. }\end{array}$ & $\begin{array}{l}\text { (HERNÁNDEZ et } \\
\text { al., 2000, p. 19). }\end{array}$ \\
\hline $\begin{array}{l}\text { “[...] conjunto de alterações que afetam } \\
\text { pontos-chave e eixos constitutivos da } \\
\text { organização do ensino universitário } \\
\text { provocadas por mudanças na sociedade ou } \\
\text { por reflexões sobre concepções intrínsecas à } \\
\text { missão da Educação Superior". }\end{array}$ & $\begin{array}{l}\text { (MASETTO, 2004, } \\
\text { p. 197). }\end{array}$ \\
\hline $\begin{array}{l}\text { "Entendemos que a inovação requer uma } \\
\text { ruptura necessária que permita reconfigurar } \\
\text { o conhecimento para além das regularidades } \\
\text { propostas pela modernidade. Ela pressupõe, } \\
\text { pois, uma ruptura paradigmática e não } \\
\text { apenas a inclusão de novidades, inclusive } \\
\text { as tecnológicas. Nesse sentido envolve } \\
\text { uma mudança na forma de entender o } \\
\text { conhecimento". }\end{array}$ & $\begin{array}{l}\text { (CUNHA, 2004, } \\
\text { p. 13). }\end{array}$ \\
\hline
\end{tabular}

(continua) 


\begin{tabular}{|l|l|}
\hline \multicolumn{1}{|c|}{ Definição } & Autor(es) \\
\hline $\begin{array}{l}\text { "[...] aspectos que podem ser importantes } \\
\text { para caracterizar a inovação educacional - } \\
\text { novidade efetiva em relação ao que já existe, } \\
\text { intencionalidade, identidade dos proponentes, } \\
\text { envolvimento dos professores, benefícios, } \\
\text { durabilidade, etc." }\end{array}$ & (TERRAZZAN, \\
\hline
\end{tabular}

Fonte: elaborado pela autora, 2016.

Como se pode constatar, inovação é um conceito polissêmico e que comporta ideologias diversas. No entanto, a intenção de melhoria, a ideia de realizar algo novo, a intenção e o planejamento parecem ser centrais para que uma mudança possa ser considerada inovação (itálico no Quadro 1).

Cortela (2016), com base em Nardi, Bastos e Terrazzan (2008), reúne os seguintes critérios, dentre outros, para que algo seja considerado como inovação educacional: (1) novidade; (2) originalidade; (3) raridade; (4) racionalidade; (5) melhoria; (6) proponentes. Representam, respectivamente, que (1) nem sempre o que é considerado como novo para um sujeito é novo em relação ao que já existe; (2) a ideia é original ou mesmo a forma como é posta em prática o é; (3) representa um processo incomum, demanda tempo de vigência e/ou incorporação das novas práticas; (4) planejamento de ações e/ou materiais com embasamento teórico; (5) os efeitos da inovação representam melhoria ou aperfeiçoamento do que já se tem; (6) quem a propõe, quem a põe em prática e a quem atende. 
Ferretti (1995) elenca também algumas subdivisões, em termos de aspectos contemplados: A- inovações curriculares, B- métodos e técnicas; C- materiais instrucionais e tecnologia educacional; D- relação professor-aluno, E- avaliação educacional. Representam, respectivamente: o planejamento do currículo, respeitando-se os limites das disciplinas, mas organizando-as em termos de novas demandas; utilização de metodologias ativas, criando e/ou empregando recursos audiovisuais e tecnologia educacional; o professor como facilitador/mediador e o aluno como sujeito do processo; avaliação com caráter formativo e contínuo.

\section{ANÁLISE E DISCUSSÃO DOS DADOS}

A IES analisada tem, atualmente, aproximadamente 3.800 docentes e oferece 154 cursos de graduação, dentre outros. Em 2013, foi solicitado aos docentes da instituição que apresentassem trabalhos descrevendo práticas realizadas no ensino de graduação e consideradas por eles como "inovadoras". No entanto, os proponentes não explicitam na chamada do evento, e nem na abertura do material publicado (OLIVEIRA; SPAZZIANI; OLIVA, 2014), o que compreendem por "práticas inovadoras". Ou seja, ficou a cargo de cada sujeito analisar se aquilo que faz é inovador e decidir compartilhar a experiência.

Os interessados deveriam elaborar resumos (máximo de duas páginas, sem referências), de forma a ressaltar os seguintes pontos: curso onde a prática foi aplicada, número de alunos envolvidos, metodologias e critérios de avaliação. 
De acordo com os organizadores, foram selecionados 58 trabalhos, sendo que alguns deles (nove), por indicação de pareceristas, foram apresentados no evento de forma oral, e os demais, em forma de pôsteres virtuais, apresentados em sessões coordenadas. Não há menção de quantos trabalhos foram apreciados.

O resultado aqui compilado demonstra claramente o envolvimento de grande parte dos docentes desta universidade pública com as demandas do mundo globalizado e a preocupação da comunidade em atingir pedagógica, cultural e socialmente os estudantes com características em evidente transformação (OLIVEIRA; SPAZZIANI; OLIVA, 2014, p. 3).

Discordando-se da afirmação acima, considera-se o relato de 58 práticas um número muito baixo frente à quantidade de docentes da universidade (menos de $2 \%$ do total). Uma das interpretações para esse índice seria a forma como os professores podem ter compreendido o que são "práticas inovadoras", vinculando-as somente ao uso de tecnologias da informação e da comunicação (TIC), por exemplo. Assim, mesmo possuindo "práticas inovadoras", o docente pode não tê-las identificado como tal, por elas não estarem associadas ao uso das TIC.

Outra possibilidade pode ter sido o fato de o professor ter de escrever sobre a própria prática e esse relato passar pelo crivo dos pares. De acordo com Cunha (2010), muitos docentes universitários resistem a enfrentar a sistematização escrita sobre aquilo que realizam. Argumenta-se aqui que essa dificuldade pode ser decorrente da falta de fundamentação 
teórica da área educacional, uma vez que muitos deles são leigos em termos de formação para a profissão docente.

Outro fator pode ser decorrente da forma como se dá a valorização do trabalho na universidade pública, uma vez que os critérios de avaliação da qualidade do docente universitário concentram-se na produção acadêmica. Assim, ensino e pesquisa tornam-se atividades concorrentes, e, como a segunda é muito mais valorizada, a docência acaba sendo relegada ao segundo plano ou mesmo a plano nenhum (CORTELA, 2013).

Dos 58 trabalhos publicados, 22 referem-se à área de ciências biológicas, doze à de ciências exatas e 24 à de ciências humanas. O critério de elegibilidade dos materiais a serem analisados foi o de selecionar apenas os resumos apresentados de forma oral, num processo de amostragem ( $9 \approx 15,51 \%$ do total). Ou seja, somente aqueles trabalhos considerados pelos pareceristas como "mais inovadores", dentro de uma quantidade previamente estabelecida. O propósito foi garantir que a prática descrita fosse também reconhecida como "inovadora" por outros sujeitos, que não somente os autores dos trabalhos.

A metodologia utilizada para análise dos resumos foi aquela desenvolvida por Bardin, 1994.

[...] um conjunto de técnicas de análise das comunicações que visa obter, por procedimentos sistemáticos e objetivos de descrição de conteúdos das mensagens, indicadores que permitam a inferência de conhecimentos relativos às condições de produção dessas mensagens (BARDIN, 1994, p. 37). 
A análise por categorias faz parte desse conjunto de técnicas. Funciona por operações de desmembramento do conteúdo em unidades, seguindo processos de fragmentação e classificação do conteúdo, efetuando reagrupamentos analógicos segundo o gênero, com critérios previamente definidos (BARDIN, 1994). Dentro da análise categorial, existe uma técnica denominada análise temática e que foi utilizada como referencial analítico neste trabalho. Essa é constituída por três etapas: 1- pré-análise; 2- exploração do material; 3- tratamento dos resultados e interpretação.

Dos nove trabalhos analisados, três remetem diretamente à abordagem sociointeracionista; três a projetos interdisciplinares; e três apontam para o uso de TIC, representando somente $5,17 \%$ do total de trabalhos, contrariando o senso comum de se associar inovação unicamente ao uso de TIC. Um trabalho refere-se a curso de Engenharia, um a de Veterinária, um a de Medicina e seis $(10,34 \%$ do total) referem-se a cursos de licenciatura.

O Quadro 2 sistematiza como os autores dos trabalhos enunciam suas práticas a partir de palavras retiradas dos textos originais, ou seja, as significações que os sujeitos dão os conceitos, que podem não ser os mesmos daqueles apresentados pelos teóricos. O segundo critério de seleção foi o de analisar somente aqueles trabalhos que estão diretamente ligados a cursos de licenciatura (6), por ser esse o foco da pesquisa maior. 
Quadro 2 - Síntese de trabalhos a partir de recortes dos textos originais

\begin{tabular}{|c|c|c|c|}
\hline $\mathbf{R}$ & $\begin{array}{c}\text { Curso / } \\
\text { disciplina }\end{array}$ & $\begin{array}{c}\text { Objetivo(s) da } \\
\text { prática }\end{array}$ & Abordagem \\
\hline II & $\begin{array}{l}\text { Ciências } \\
\text { Biológicas/ } \\
\text { Matemática } \\
\text { Aplicada }\end{array}$ & $\begin{array}{l}\text { Produção ou } \\
\text { edição de vídeos } \\
\text { sobre tema } \\
\text { pesquisado e uso } \\
\text { de redes sociais. }\end{array}$ & $\begin{array}{c}\text { Modelagem } \\
\text { matemática; blended } \\
\text { learning. }\end{array}$ \\
\hline III & $\begin{array}{l}\text { Licenciatura em } \\
\text { Física/ Didática } \\
\text { da Ciência }\end{array}$ & $\begin{array}{c}\text { Garantir a } \\
\text { coerência entre o } \\
\text { ensino praticado } \\
\text { na universidade e } \\
\text { aquele esperado } \\
\text { dos licenciandos } \\
\text { (simetria } \\
\text { invertida). }\end{array}$ & $\begin{array}{c}\text { Metacognição; } \\
\text { sociointeracionismo; } \\
\text { CTSA e HFC. }\end{array}$ \\
\hline IV & $\begin{array}{l}\text { Licenciatura } \\
\text { em Letras/ } \\
\text { aplicável em } \\
\text { diferentes } \\
\text { cursos }\end{array}$ & $\begin{array}{l}\text { Desenvolvimento } \\
\text { da autonomia, } \\
\text { trabalho coletivo, } \\
\text { respeito aos } \\
\text { diferentes ritmos } \\
\text { de aprendizagem. }\end{array}$ & $\begin{array}{c}\text { Estações de } \\
\text { aprendizagem } \\
\text { (Stationenlemen). }\end{array}$ \\
\hline V & $\begin{array}{l}\text { Licenciatura em } \\
\text { Matemática/ } \\
\text { Física Geral II }\end{array}$ & $\begin{array}{l}\text { Planejamento de } \\
\text { uma aula de Física } \\
\text { para o ensino } \\
\text { médio, usando } \\
\text { como recurso } \\
\text { pelo menos uma } \\
\text { tecnologia digital. }\end{array}$ & $\begin{array}{l}\text { Aprendizagem } \\
\text { significativa, } \\
\text { tecnologia como } \\
\text { ferramenta } \\
\text { mediadora. }\end{array}$ \\
\hline
\end{tabular}

(continua) 


\begin{tabular}{|c|c|c|c|}
\hline $\mathbf{R}$ & $\begin{array}{c}\text { Curso / } \\
\text { disciplina }\end{array}$ & $\begin{array}{c}\text { Objetivo(s) da } \\
\text { prática }\end{array}$ & Abordagem \\
\hline VI & $\begin{array}{l}\text { Licenciatura em } \\
\text { Letras/ Centro } \\
\text { de Línguas } \\
\text { Estrangeiras }\end{array}$ & $\begin{array}{c}\text { Aprendizagem } \\
\text { de línguas } \\
\text { estrangeiras e } \\
\text { culturas através do } \\
\text { contexto virtual. }\end{array}$ & $\begin{array}{l}\text { Transculturalidade; } \\
\text { socioconstrutivismo; } \\
\text { TIC. }\end{array}$ \\
\hline VII & $\begin{array}{c}\text { Licenciatura } \\
\text { em Ciências } \\
\text { Biológicas/ } \\
\text { Estágio } \\
\text { Supervisionado } \\
\text { e Educação, } \\
\text { Escola e } \\
\text { Professor }\end{array}$ & $\begin{array}{l}\text { Articulação entre } \\
\text { as reflexões } \\
\text { teóricas } \\
\text { desenvolvidas em } \\
\text { cada disciplina } \\
\text { e a realidade } \\
\text { observada e } \\
\text { vivenciada na } \\
\text { escola. }\end{array}$ & $\begin{array}{c}\text { Projeto } \\
\text { interdisciplinar. }\end{array}$ \\
\hline
\end{tabular}

Fonte: elaborado pela autora, 2016.

Apesar de tratar de prática desenvolvida em curso de licenciatura, o resumo III foi retirado por questão ética, por ter sido elaborado pela autora deste trabalho.

O Quadro 3 sintetiza as análises realizadas a partir dos critérios elencados. Os resumos (R) estão numerados em algarismos romanos, e as categorias analisadas estão agrupadas em dois blocos, seguindo os critérios de Nardi et al. (2008). Foi excluída da análise a categoria (6) proponentes, uma vez que todos os trabalhos tiveram os autores como proponentes. São elas: novidade; originalidade; raridade; racionalidade; melhoria. Os critérios de Ferretti (1995) são indicados de A a E, considerando 
inovação com relação a: A- currículo, B- métodos e técnicas; C- uso de tecnologia educacional; D- relação professor-aluno, E- avaliação educacional.

$\mathrm{O}(\mathrm{x})$ em cada célula representa a presença do critério no texto apresentado pelo autor, $(n)$ indica que não atende ao critério e o espaço em branco (-) indica que o critério não foi informado pelo autor. A última coluna registra a quantidade de critérios atendidos, sendo dez o máximo e zero, o mínimo.

Quadro 3 - Atendimento dos critérios elencados pelos referenciais de análise

\begin{tabular}{|c|c|c|c|c|c|c|c|c|c|c|c|}
\hline \multirow[t]{2}{*}{$\mathbf{R}$} & \multicolumn{5}{|c|}{ NARDI et al. (2008) } & \multicolumn{5}{|c|}{ FERRETI (1995) } & \multirow[b]{2}{*}{$\Sigma$} \\
\hline & $\begin{array}{l}\frac{0}{0} \\
\frac{\pi}{0} \\
\frac{0}{2} \\
0 \\
0\end{array}$ & 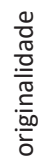 & $\begin{array}{l}\frac{0}{0} \\
\frac{\pi}{0} \\
\frac{0}{\frac{0}{\pi}} \\
\end{array}$ & $\begin{array}{l}\frac{0}{0} \\
\frac{\pi}{0} \\
\frac{0}{\pi} \\
\frac{\pi}{c} \\
.0 \\
\frac{0}{U} \\
\frac{\pi}{2}\end{array}$ & 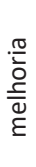 & $A$ & B & C & D & $E$ & \\
\hline II & $x$ & $x$ & $\mathrm{n}$ & $x$ & $x$ & $x$ & $x$ & $x$ & $x$ & $x$ & 9 \\
\hline IV & $x$ & $\mathrm{n}$ & $x$ & $x$ & $x$ & $x$ & $x$ & $x$ & $x$ & $x$ & 9 \\
\hline $\mathrm{V}$ & $x$ & $\mathrm{n}$ & $\mathrm{n}$ & $x$ & - & - & $x$ & $x$ & $x$ & - & 5 \\
\hline VI & $x$ & $x$ & $x$ & $x$ & $x$ & $x$ & $x$ & $x$ & $x$ & $x$ & 10 \\
\hline VII & $x$ & $\mathrm{n}$ & $x$ & $x$ & - & $x$ & $x$ & $\mathrm{n}$ & - & $x$ & 6 \\
\hline
\end{tabular}

Fonte: elaborado pela autora, 2016.

Os dados apontam que três trabalhos $(33,4 \%$ daqueles indicados por pareceristas) atendem à maioria (nove a dez) dos critérios apontados pelos autores para serem considerados inovadores. Dois dos trabalhos (23\% dos indicados por pareceristas) não atendem - ou não apresentam informações suficientes para que sejam considerados trabalhos inovadores 
na maioria dos quesitos apontados -, contemplando cinco ou seis dos dez critérios elencados.

Após a análise global dos trabalhos, procedeu-se às análises individuais, descritas a seguir.

R. II: Vídeos e redes sociais: exemplo de práticas docentes para disciplinas de Matemática.

O autor relata que faz parte de um grupo de pesquisa em informática, outras mídias e educação matemática; que as atividades de ensino ocorrem em curso de Ciências Biológicas, na disciplina de Matemática Aplicada; que os alunos são orientados a elaborarem vídeos e a usarem redes sociais para a divulgação de conteúdos e temas, a partir da Modelagem Matemática, efetuando trabalhos em grupo a partir de temas escolhidos por eles, utilizando-se de metodologias de ensino ativas. O autor informa os critérios de avaliação, diz que essa é processual e que atua como orientador no processo de construção dos trabalhos. Esse trabalho atende a nove dos dez critérios adotados para se considerar a atividade como inovadora.

R. IV: Discutir, refletir, aprender em "estações de aprendizagem": o ensino com foco no aluno.

A autora explica que esse método de trabalho foi desenvolvido por Parkhurst nos anos 20 do século XX, com o intuito de lidar com as dificuldades das diferenças de idade de alunos. Mais tarde, passou a ser utilizado em atividades esportivas (circuit training) e, a partir dos anos 1990, também em outras disciplinas. Cabe ao professor preparar diferentes "estações", 
com atividades previamente elaboradas, equipadas com instruções e materiais adequados para que sejam realizadas. Elas são distribuídas em um mesmo espaço físico e buscam desenvolver diferentes habilidades, tais como a realização de exercícios, um experimento, a produção de um texto, a tradução, dentre outros. O tempo é determinado pelo professor, e os alunos "passam" pelas diversas "estações" e cumprem as atividades propostas. A autora atua na área de Letras Modernas, no ensino do alemão. Não faz menção do uso de TIC, mas elas estão implícitas numa das "estações" descritas. Esse trabalho atende a nove dos dez critérios adotados para se considerar a atividade como inovadora.

R. V: Aprendendo a ensinar com tecnologias: o uso da ferramenta da WEB 2.0 em curso de licenciatura.

Os autores relatam que essa atividade foi desenvolvida num curso de licenciatura em Matemática, na disciplina Física Geral II. Objetivou ensinar os conteúdos fazendo uso de TIC, explorando experimentos virtuais, vídeos e blog. Após aprenderem sobre essas tecnologias, os alunos foram orientados a criarem coletivamente planos de aula por meio de um blog, efetuando comentários e debates por essa ferramenta. $O$ trabalho, apesar de apresentar pontos positivos, não explora alguns dos critérios estabelecidos, tais como número de alunos envolvidos, procedimentos de avaliação, conteúdos explorados e relação professor-aluno. No final, os autores afirmam que a experiência, apesar de considerada significativa pelos alunos, não foi suficiente para abalar as concepções deles sobre ensino e aprendizagem. Esse trabalho 
atende a apenas cinco dos dez critérios adotados para se considerar a atividade como inovadora.

R. VI: Teletandem: o desenvolvimento das competências oral e intelectual em línguas estrangeiras de graduando da UNESP no século XXI.

Esse trabalho faz parte de um projeto de pesquisa maior e foi desenvolvido junto a alunos de graduação do curso de Letras da instituição e de universidades estrangeiras que visam aprender línguas nativas, a partir da exploração da dimensão cultural. Usam, como recursos, aplicativos de mensagem instantânea, vídeo, Skype, dentre outros. Como aporte teórico, o autor utiliza-se do conceito de transculturalidade; afirma que o projeto traz características de ensino e de pesquisa; e que os oito anos de vigência têm possibilitado a formação de profissionais na área, além de colaborar no processo de internacionalização da IES. Esse trabalho atende a todos os dez critérios adotados para se considerar a atividade como inovadora.

R. VII: Formação docente e complexidade da escola: articulação das disciplinas pedagógicas e estágios num curso de licenciatura em Ciências Biológicas.

Trata-se de um projeto interdisciplinar que visa integrar disciplinas pedagógicas com as de estágio supervisionado a partir de temas estabelecidos em cada uma das disciplinas. O resumo descreve brevemente o que é feito em cada uma das etapas, a forma como são feitas as avaliações. Faltam informações relevantes que auxiliem na compreensão de pontos importantes, tais como: quantos alunos foram envolvidos, que 
tipo de dados foram coletados junto às escolas visitadas, quais os referenciais utilizados nas atividades propostas. Mesmo assim, a novidade e a raridade em relação à aproximação de disciplinas dentro de um projeto interdisciplinar que visa à exploração de temas relevantes são fatores importantes no trabalho. Ele atende a seis dos dez critérios adotados para se considerar a atividade como inovadora.

\section{CONSIDERAÇÕES FINAIS}

De modogeral, a maioria dos autores considera que as atividades desenvolvidas por eles são uma nova forma de trabalho para si, mas não necessariamente original; apresentam potencial de melhoria no processo de aprendizagem, apesar de não haver informações a respeito de parâmetros de comparação na quase totalidade dos casos; descrevem atividades que foram estruturadas, apontando aspectos de racionalidade; fazem uso de metodologias ativas, apesar de não haver informações, em muitos deles, sobre o grau de participação dos alunos na elaboração do curso ou nas atividades propostas; e não desvinculam o conceito de inovação e/ou as metodologias de ensino ao uso de tecnologias de informação e comunicação.

O objetivo da IES, ao promover esse evento, era o de levantar as práticas já existentes com vistas a elaborar diretrizes para a implantação de um programa de estímulo ao uso de metodologias inovadoras na universidade, num tipo de formação continuada. Nesse sentido, também essa IES inova ao propor programas dessa natureza, uma vez que ainda são poucas as universidades públicas que adotam ações formativas para os docentes. 
No entanto, este tipo de iniciativa da IES é importante, mas não suficiente. A construção de uma identidade docente passa também pela adoção de políticas institucionais que assegurem efetiva valorização da atividade de ensino, além da oferta de formação em serviço, visando propiciar momentos em que os docentes possam refletir coletivamente sobre o que fazem, apoiados em referenciais nos quais possam se fundamentar teoricamente, buscando melhorias das práticas educativas e pela adoção de políticas de valorização das atividades de ensino por meio de ações de gestão.

É preciso trabalhar em prol da ideia de desenvolvimento profissional: um processo gradual, ininterrupto, coletivo, articulado com condições materiais e sociais de trabalho, reconhecimento profissional e momentos de formação em serviço. Ou seja, enfrentar o desafio de romper com lógicas há muito estabelecidas, o que requer, além de empenho individual, um esforço para a discussão de problemas e compromisso com as decisões coletivas.

\section{REFERÊNCIAS}

ALARCÃO, I. Profissionalização docente. Anais ... do II Congresso Internacional sobre Formação do Professores nos Países de Língua e Expressão Portuguesa. 1998, p. 100-118.

ALMEIDA, M. I. Formação do professor do ensino superior: desafios e políticas institucionais. São Paulo: Cortez, 2012.

BARDIN, L. Análise de conteúdo. Lisboa: Edições 70, 1994. 
BRASIL. Resolução CNE/CP 01/2002, de 18 de fevereiro de 2002. Institui diretrizes curriculares nacionais para a formação de professores da educação básica, em nível superior, curso de licenciatura, de graduação plena. DOU, Brasília, 9 abr. 2002. Seção 1, p. 8.

BRASIL. Resolução CNE 02/2015, de 01 de julho de 2015. Estabelece as diretrizes curriculares nacionais para formação inicial em nível superior (cursos de licenciatura, cursos de formação pedagógica para graduados e cursos de segunda licenciatura) e para a formação continuada. DOU. Brasília. 02/07/2015. Sessão 1, p. 8-12.

CORTELA, B. S. C. Professor universitário: o desafio da construção de uma profissionalidade docente. In: SILVA, L. F; DIAS, M. S; MANZANI, R. M (Org.). Cadernos de docência na educação básica II. São Paulo: Cultura Acadêmica, 2013, p. 9-28.

CORTELA, B. S. C. Uma experiência de ensino em didática da ciência: associando resultados de pesquisas à docência no ensino superior. In: III CONGRESSO NACIONAL DE FORMAÇÃO DE PROFESSORES (CNFP) E XIII CONGRESSO ESTADUAL PAULISTA SOBRE FORMAÇÃO DE EDUCADORES (CEPFE). Águas de Lindóia, 11 a 13 abril de 2016.

CUNHA, M. I. Inovações pedagógicas e a reconfiguração de saberes no ensinar e no aprender na universidade. Anais ... VIII CONGRESSO LUSO-AFRO-BRASILEIRO DE CIÊNCIAS SOCIAIS. Coimbra, Portugal, 2004, p. 1-16.

CUNHA, M. I. Trajetórias e lugares de formação da docência universitária: da perspectiva individual ao espaço institucional. Araraquara, SP: Junqueira \& Marin; Brasília: CAPES: CNPq, 2010.

FERRETTI, C. J. A inovação na perspectiva pedagógica. In: GARCIA, W. E. (Coord.). Inovação educacional no Brasil: 
problemas e perspectivas. Campinas: Autores Associados, 1995, p. 61-83.

GARCIA, C. M. Formação de professores: para uma mudança educativa. Porto, Portugal: Porto Editora, 1999.

GAUTHIER, C. et al. Por uma teoria da pedagogia: pesquisas contemporâneas sobre o saber docente. Ijuí: Editora UNIJUÍ, 1998.

GOLDBERG, M. A. A. Inovações educacionais: a saga de sua definição. In: GARCIA, W. E. (Coord.). Inovação educacional no Brasil: problemas e perspectivas. Campinas: Autores Associados, 1995, p. 197-209.

HERNÁNDEZ et al. Aprendendo com as inovações nas escolas. Porto Alegre: Artes Médicas Sul, 2000. 308p.

MASETTO, M. T. (Org.). Docência na universidade. 4. ed. Campinas, SP: Papirus, 2002.

MASETTO, M. T. Competência pedagógica do professor universitário. São Paulo: Summus, 2003.

NARDI, R.; BASTOS, F.; TERRAZZAN, E. A. Práticas pedagógicas e processos formativos de professores na área de ciências e matemática. Bauru, UNESP, 2008. (Relatório de pesquisa referente a projeto financiado pelo Conselho Nacional de Desenvolvimento Científico e Tecnológico - (NPq).

NÓVOA, A. (Org.). Os professores e a sua formação. Lisboa: Dom Quixote, 1992.

PIMENTA, S. G.; ANASTASIOU, L. G. C. Docência no ensino superior. São Paulo, Cortez, 2002. 
PIMENTA, S. G.; GHEDIN, E. (Org.). Professor reflexivo no Brasil: gênese e crítica de um conceito. São Paulo: Cortez, 2006.

OLIVEIRA, J. B. B.; SPAZZIANI, M. L.; OLIVA, V. N. L. S. (Org.). Cadernos Prograd: Coletânea das Experiências de Inovação na Graduação da UNESP [recurso eletrônico]. São Paulo: Universidade Estadual Paulista, Pró-Reitoria de Graduação, 2014. 144 p. Disponível em: <http://www. unesp.br/prograd>. Acesso em: 18 jan. 2016.

SÃO PAULO (Estado). Deliberação CEE N 126/2014, de 04/06/2014. Institui diretrizes curriculares complementares para a formação de docentes para a educação básica nos cursos de graduação de pedagogia, normal superior e licenciaturas. DOE 5 jun. 2014. Sessão I, p. 28.

TERRAZZAN, E. A. Dilemas e perspectivas para inovação educacional. Projeto de pesquisa - Universidade Federal de Santa Maria, Santa Maria/RS, 2006.

ZABALZA, M. A. O ensino universitário: seu cenário e seus protagonistas. Porto Alegre: Artmed, 2004.

\begin{abstract}
This work is a reflection on the practice of university professors working in undergraduate teaching programs. It seeks to indicate what a group of professors from different courses at a public university understand by innovative practices in undergraduate education, from their description of the activities they perform. Data were collected from abstracts presented at an event organized by the institution and were analyzed from Bardin's perspective of content analysis. Results
\end{abstract}


show that most authors consider the activities they developed and described are a new way of working for themselves, not necessarily original. Some potential for improvement in the learning process is demonstrated and the use of active methodologies - not exactly associated with technologies - is also mentioned. It is believed that studies on these professionals ' practices can help elucidate factors involving the building process of a professional identity in higher education.

Keywords: University teaching. Innovative practices. Undergraduate education. Professor's identity.

\section{Beatriz S. C. Cortela}

Doutora em Educação para Ciência pela UNESP, Bauru; licenciada em Física pela Universidade Federal de São Carlos e licenciada em Matemática pela Universidade Estadual do Norte de Paraná. Docente do Departamento de Educação da UNESP, Bauru, e do Programa de Pós-Graduação em Educação para Ciência, ministrando as disciplinas: Didática da Ciência, Metodologia e Prática de Ensino de Física, Docência no Ensino Superior: Abordagens de Ensino.

biacortela@fc.unesp.br 